\title{
TAM Receptor Signalling and Demyelination
}

\author{
Michele D. Binder Trevor J. Kilpatrick
}

Florey Neuroscience Institutes and Centre for Neuroscience, The University of Melbourne, Parkville, Vic., Australia

\section{Key Words}

TAM receptor signalling $\cdot$ Demyelination $\cdot$ Tyrosine kinase $\cdot$ Multiple sclerosis

\begin{abstract}
The TAM family (Tyro3, Axl and Mer) of receptor protein tyrosine kinases play pivotal roles in a number of major cellular processes: cell survival and proliferation, immunomodulation and phagocytosis. These processes are central to both the initial development and pathological course of human multiple sclerosis. All three receptors and their ligands, Gas6 (growth arrest-specific gene 6) and protein $S$, are expressed in the central nervous system (CNS), including in oligodendrocytes, the myelin-producing cell of the CNS. Recent studies have shown that Gas6-dependent TAM receptor signalling is an important modulator of oligodendrocyte survival and microglial phenotype both in vitro and in vivo. Multiple lines of evidence allow us to hypothesise that, during a demyelinating challenge, dysfunctional TAM receptor signalling could lead to a 'vicious cycle' of cell death, reduced phagocytosis and deleterious immune hyper-activation. A current challenge in this field is to expand our understanding of TAM receptor signalling from rodent models of central demyelination to human disease.
\end{abstract}

Copyright $\odot 2009$ S. Karger AG, Base
(C) 2009 S. Karger AG, Base

$1424-862 X / 09 / 0174-0277 \$ 26.00 / 0$

Fax +41613061234

E-Mail karger@karger.ch

www.karger.com
Multiple sclerosis (MS) is a complex demyelinating disease of the central nervous system (CNS). The initiating insult in MS remains unknown. However, it is clear that the pathology of MS involves complex interactions between many systems and cell types, including both the adaptive and innate immune systems, nerve cells and glial cells. Although the majority of research in MS has focussed on the role of adaptive immunity in the development and progress of the disease, it has recently become clear that, at least in some cases, the primary insult could be directed at the oligodendrocyte. In a seminal study in 2004, Barnett and Prineas [1] examined newly forming lesions from MS patients. They found that prior to the onset of extensive demyelination, and in the absence of cells of the adaptive immune system, oligodendrocyte apoptosis could be detected, generally in the presence of increased numbers of microglia. This work points to oligodendrocyte apoptosis as an early event in the formation of a lesion, and also indicates that microglia could have an important role to play in the initial development of an MS lesion.

Our laboratory has principally focussed on the neurobiological component of MS. In particular, it is clear that one potential strategy for preventing or ameliorating demyelination is to inhibit the death of damaged oligodendrocytes. We have previously shown this strategy to be successful in mouse models of central demyelination whereby provision of exogenous leukaemia inhibitory 
Fig. 1. Schematic of TAM receptors and their ligands protein S and Gas6. a The three members of the TAM receptor family (Tyro3, Axl and Mer) have a common domain structure, with two N-terminal immunoglobulin-like domains, two fibronectin III (FNIII)-like domains, a single-pass transmembrane domain and a cytoplasmic protein tyrosine kinase (PTK) domain containing a number of phosphorylation sites. b The two TAM receptor ligands, protein $\mathrm{S}$ and Gas6, also share a common domain structure, with an N-terminal Gla domain (a region which is $\gamma$-carboxylated in a vitamin-D-dependent posttranslational modification), four epidermal growth factor (EGF)-like domains and two laminin-G (LG) domains. c Binding of the ligand to the two immunoglobulin domains of the receptor is mediated via the LG1 region of the ligand. Formation of a 1:1 ligand:receptor complex initiates formation of a heterotetrameric complex with a 2:2 ligand:receptor ratio.

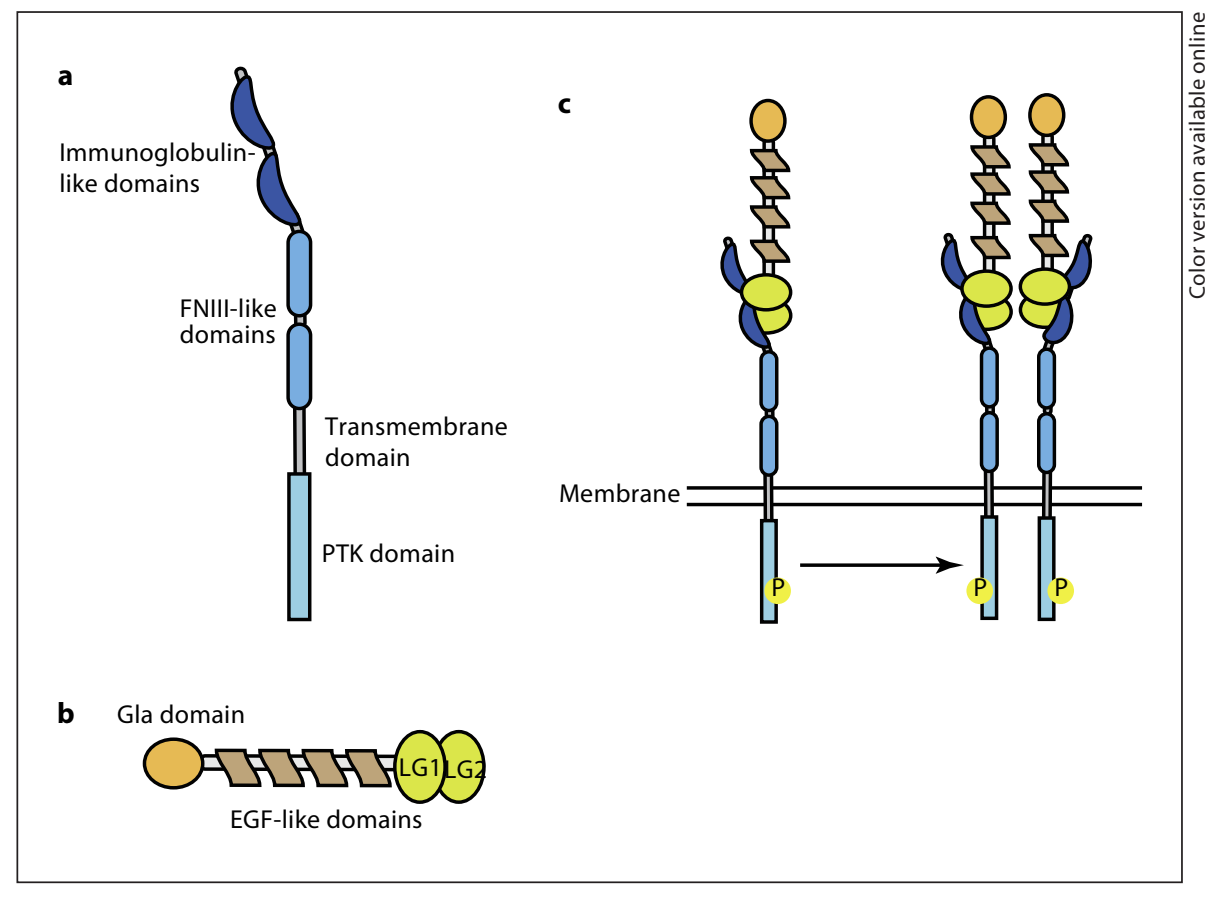

factor can prevent loss of oligodendrocytes and improve clinical outcome in experimental allergic encephalomyelitis [2] and in cuprizone-mediated demyelination [3].

In order to identify novel factors potentially important in oligodendrocyte survival, our laboratory employed a microarray strategy, investigating the expression of genes in mice during experimentally induced demyelination compared to control mice. Using this strategy, we identified the TAM receptor family as potentially important, with all members of the family regulated during demyelination.

\section{Structure of the TAM Receptors and Ligands}

The TAM receptors are three related protein receptor tyrosine kinases that were first cloned in 1991 as orphan receptors [4]. The three structurally related receptors, Tyro3, Axl and Mer, are collectively known as the TAM receptors. These receptors were reported to be widely expressed in the vertebrate nervous system [4].

The three receptors have the defining structure of two $\mathrm{N}$-terminal immunoglobulin (IG) domains, followed by two fibronectin-III-like domains attached by a singlepass $\alpha$-helical transmembrane domain to an intracellular tyrosine kinase domain (fig. 1a) [5-7]. In common with other receptor tyrosine kinases, the functional form of the receptor is a dimer, and the receptors have been reported to form both hetero- and homodimers [8]. Analysis of the structure of receptor-ligand complexes has determined that the two N-terminal immunoglobulin domains mediate binding to the ligand (fig. 1c) [9].

The growth arrest-specific gene 6 (Gas6) was first identified as a gene upregulated in response to growth arrest in serum-starved NIH 3T3 cells [10]. The mouse and the human genes were subsequently cloned and fully characterised, with the human Gas6 showing a similar pattern of expression in serum-starved human fibroblasts [11]. The protein was identified as structurally related to protein $S$, an important component of the anticoagulation cascade [11-13]. It was subsequently identified that both Gas6 and protein S were ligands for the TAM receptors [14-16]. The assignment of protein $S$ as a ligand for the TAM receptors was initially controversial, as original observations found that Gas6, but not protein S, could be co-immunoprecipitated with TAM-Fc fusion proteins [14]. Further, other authors had previously shown that whilst human protein $S$ was a potent activator of mouse Tyro3, they could not identify that human protein $S$ was able to activate human Tyro3 [17]. However, more recent results have unequivocally shown that protein $S$ functions as a ligand for both the Mer and Tyro3 receptors, although its status as a ligand for the Axl receptor remains unproven $[18,19]$. 
The two ligands, protein $S$ and Gas6, have a unique structure not found elsewhere in the vertebrate proteome. At the N-terminus of the protein is the Gla domain (a region containing $11 \gamma$-carboxyglutamic acid residues), followed by 4 epidermal growth factor (EGF)-like domains and 2 laminin-G (LG) domains which together form the sex-hormone-like binding domain (fig. 1b) [11, 20, 21]. Both ligands are dependent upon vitamin $\mathrm{K}$ for post-translational modification of the Gla domain, as when warfarin is used to block vitamin-K-dependent $\gamma$-carboxylation, at least some of the observed functions of the ligands are abolished, including protection of fibroblasts from apoptosis during serum starvation [for review, see 22].

The domains within Gas6 and protein $\mathrm{S}$ have been shown to exert particular functions. The Gla domain, in common with other members of the vitamin-K-dependent family of proteins, has been shown to bind negatively charged phospholipids on the surface of cell membranes. Gas6 in particular has been shown to be specific for phosphatidylserine (PS), in comparison to other phospholipids tested [23]. Protein $S$ has also been shown to bind to vesicles with PS bound to the surface, and to apoptotic cells [24].

Numerous studies have shown that the LG domains mediate binding to the TAM receptors $[9,25,26]$. In particular, examination of the crystal structure of the Gas6/ Axl complex revealed that the functional signalling complex is a heterotetramer formed from 2 receptor molecules and 2 ligand molecules in a circular structure [9]. The major binding site within the ligand was fully contained within the LG1 domain which interacts with both the IG1 and IG2 domains of the receptor, with no direct interaction in the dimer between the 2 receptor molecules or the 2 ligand molecules [9]. It is also likely that formation of the heterotetrameric complex is initiated by formation of a 1:1 receptor:ligand complex (fig. 1c).

Recently, Pierce et al. [27] provided direct evidence that at least 2 of the TAM receptors, Axl and Tyro3, can form heterodimers. Further, unpublished observations from Lemke and Rothlin [8] indicate that the ability to form both hetero- and homodimers is not restricted to Axl and Tyro3, but extends to both ligands and all 3 receptors. This ability clearly adds another potential level of complexity to the regulation of TAM receptor signalling. It has also recently been shown that in mice lacking the Mer receptor, Tyro3 expression is also markedly downregulated, indicating that disruption of signalling through 1 TAM receptor can affect expression and presumably therefore signalling through another TAM receptor [19].

TAM Receptor Signalling and Demyelination

\section{Expression of the TAM Receptors and Ligands}

As noted above, the TAM receptors and their ligands are expressed in a wide variety of tissues. These tissues include cells of the immune, vascular, reproductive and nervous systems. An excellent summary of our current knowledge of the spatial and temporal expression of the TAM receptors and ligands can be found in a recent review by Lemke and Rothlin [8]. A notable common finding has been that, unlike other tyrosine kinase receptors, the TAM receptors are not widely or highly expressed during development, although expression is still detectable, but their expression is markedly upregulated postnatally, extending into adulthood, with the profile of ligand expression following a similar pattern. This expression pattern reflects the central role TAM receptor signalling plays in regulating homeostasis in a number of different tissue types (discussed below).

In the nervous system, TAMs and their ligands have been observed to be expressed by both neurons and glial cells. Within the rodent nervous system, Tyro3 appears to be most highly expressed, with maximal levels detected from late post-natal periods (P15 in the rat) and extending into adulthood $[4,28,29]$. Tyro3 is also highly expressed in human brain tissue [30]. The expression of both Axl and Mer within the CNS is more restricted than that of Tyro3, and overall expression is lower [29].

Of particular interest is the observation that expression for all 3 receptors can be localised specifically to oligodendrocytes. This expression has been reported for both human and rodent oligodendrocytes in vitro and in vivo [29, 31-33]. In the rodent brain, all 3 TAM receptors have been observed to be upregulated in white matter areas before and during myelination, although only expression of Tyro3 persists at detectable levels in the adult [29].

Protein S and Gas6, as indicated above, are both highly upregulated after birth, and expression of both persists at high levels in the adult [34]. However, both proteins can be detected during development. At early stages of development, Gas6 expression in the rat embryo is mostly confined to non-neuronal tissues [34]. In the rat brain, Gas6 was observed to be initially expressed at E17, although expression is weak, but from the day of birth onwards Gas6 is widely expressed in numerous brain regions, including a number of cortical regions, the hippocampus, midbrain and the cerebellum [34]. The expression of Gas6 has also been described in the ventral spinal cord [35]. In contrast, protein $S$ is expressed only at low levels in the CNS, although expression has been observed in the

Neurosignals 2009;17:277-287 279 
locus coeruleus, choroid plexus [34], as well as in astrocytes [16] and in retinal pigment epithelial cells [19]. Protein $\mathrm{S}$ expression has also been observed in the rabbit brain, with mRNA and protein detected in pyramidal neurons of the deep layer of the cortex and the hippocampus, in addition to the dentate fascia neurons of the hippocampus [36]. Interestingly, a significant upregulation of the concentration of Gas6 was found in human cerebrospinal fluid (CSF) in patients with chronic inflammatory demyelinating polyneuropathy, compared to either patients with non-inflammatory/non-autoimmune disease or those with acute inflammatory demyelinating neuropathy (Guillain-Barré disease).

These observations indicate that all components of the TAM receptor-signalling pathway are expressed both at the correct developmental stage and the correct place to affect myelination in the CNS. Further, levels of Gas6 have been observed to be upregulated in at least one chronic demyelinating disease, providing a strong basis for the investigation of a potential link between TAM receptor signalling and other chronic demyelinating diseases such as MS.

\section{Function and Signalling of the TAM Receptors}

\section{Cell Survival and Proliferation}

As mentioned above, the Gas 6 gene was cloned in a screen for genes upregulated during serum starvation and the earliest studies on Gas 6 concentrated on its function in cell survival and proliferation. Gas6 has been shown to positively influence survival in numerous cell types of many lineages. In the kidney, Gas6 increases the survival of mesangial and glomerular cells, both in vitro and in vivo [37, 38]. Gas6 has also been shown to be antiapoptotic for various primary cell types and cell lines in culture, including fibroblasts $[39,40]$, vascular smooth muscle cells [41-43], endothelial cells [44-46], testicular cells [47], lens epithelial cells [41] and peripheral macrophages [48].

In the nervous system, Gas6 has been shown to have anti-apoptotic effects on a number of cell types, including neurons [27, 49, 50], Schwann cells [35], and human and rodent oligodendrocytes [31, 51, 52]. Of particular note, Shankar et al. [52] demonstrated that Gas6 could protect oligodendrocytes from tumour necrosis factor $\alpha$ (TNF $\alpha$ )-mediated toxicity, as TNF $\alpha$ is an inflammatory cytokine secreted by microglia during demyelination. Protein $S$ has been shown to function to protect neurons in an animal model of stroke [53].
In addition to exhibiting anti-apoptotic effects, Gas6 has additionally been shown to stimulate mitogenesis for a limited number of cell types including cardiac fibroblasts [54] and Schwann cells [35]. Protein S can also function as a potent mitogen for vascular smooth muscle cells [55], although it has been shown to have an anti-proliferative effect on rat astrocytes after injury [56].

Many of these studies, however, are limited to an in vitro setting, and although they clearly show that both Gas6 and protein S can rescue many cells from apoptotic cell death, there remains no clear evidence of the relative importance of TAM receptor signalling on the prevention of apoptosis under pathophysiological challenge in vivo. Insights into the potential biological relevance of TAM receptor signalling have come primarily from studies utilising mice in which either the various TAM receptors or their ligands have been knocked out. Konishi et al. [57] studied the outcome of a mouse vascular injury model in wild-type and Axl knockout mice. In this model the activation of Axl signalling, which was at least partially dependent upon Gas6, increased the vascular remodelling which is a detrimental outcome of vascular injury, and this remodelling was likely to be a consequence of increased vascular smooth muscle cell survival. Thus, although Gas6/Axl signalling has been shown to be a biologically relevant signalling pathway in injury, the engagement of this pathway does not necessarily lead to positive outcomes.

In contrast to the above study highlighting a negative role for TAM receptor-dependent survival, more recent studies focussing on the nervous system have shown a positive role for TAM receptor signalling and the accompanying potentiation of neural cell survival. Pierce et al. [27] studied the migration and survival of gonadotropinreleasing hormone (GnRH) neurons in Tyro3 and Axl single- and double-knockout mice. The authors found that in the absence of appropriate signalling from Tyro3 and Axl, apoptosis amongst migrating neurons was increased, with a resulting deficit in the number of $\mathrm{GnRH}$ neurons compared to wild-type mice. This deficit resulted in disruption of the normal oestrous cycle in the mutant mice. Studies from our own laboratory (see below) have also shown a positive effect of TAM receptor signalling during demyelination in vivo [31].

Many lines of evidence point to a critical role for the phosphatidylinositol-3-kinase (PI3K) signalling pathway in transducing the survival signal initiated by TAM receptor activation (fig. 2a) [46, 57-61]. The p85 subunit of PI3K directly binds phosphorylated tyrosine in the Axl receptor [61, 62], leading to phosphorylation and activa- 


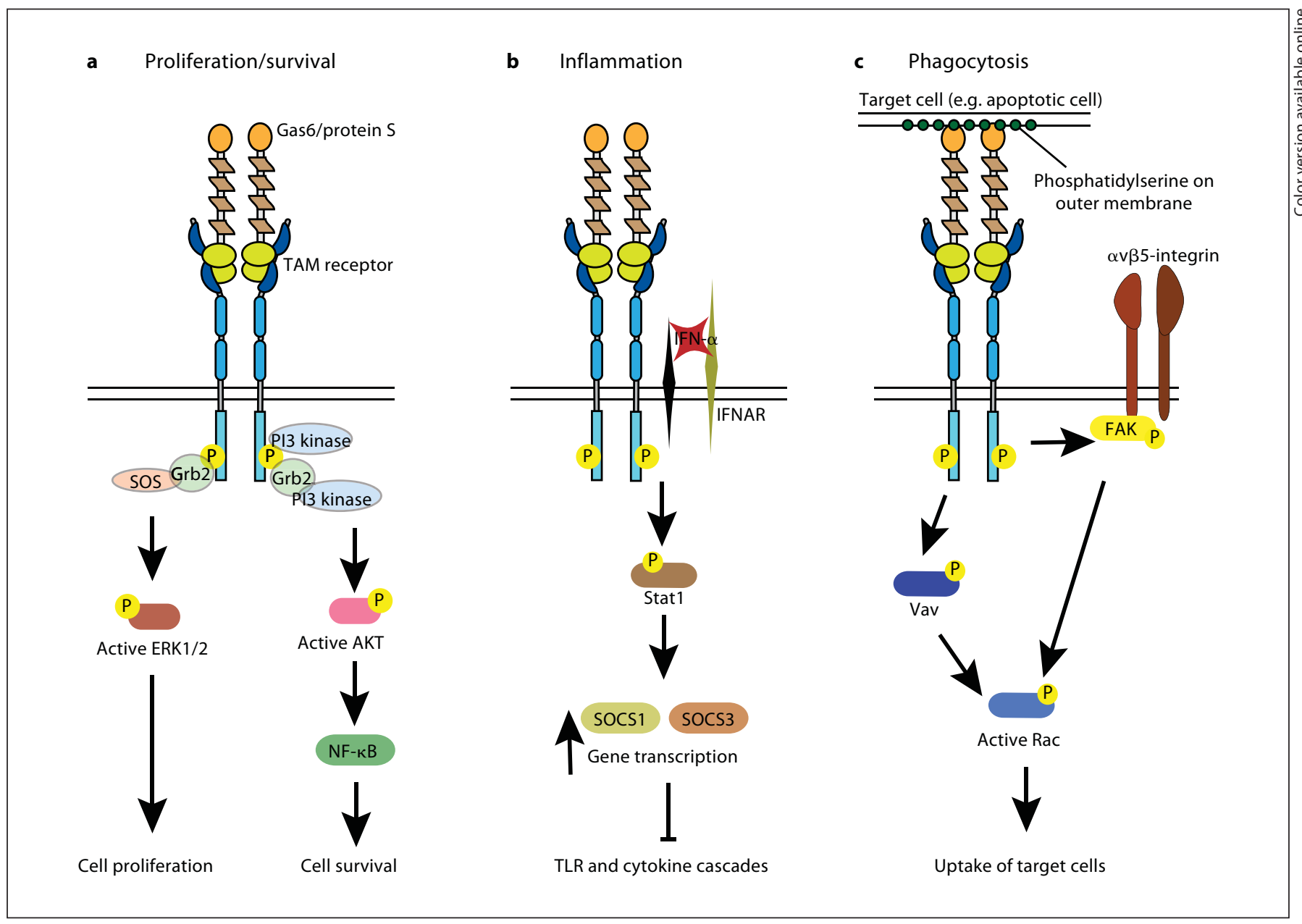

Fig. 2. Simplified TAM receptor signalling pathways. TAM receptors are phosphorylated and activated in response to ligand binding. a The phosphatidylinositol-3-kinase (PI3K) can be engaged either by direct binding of the p85 subunit of PI3K or indirectly by binding of growth factor receptor-bound 2 (Grb2) adaptor protein, leading to phosphorylated Akt and nuclear translocation of $\mathrm{NF}-\kappa \mathrm{B}$ (nuclear factor $\kappa$-light-chain enhancer of activated B cells), ultimately leading to promotion of cell survival. Alternatively, binding of the Grb2 adaptor protein and recruitment of son of sevenless (SOS) can engage the extracellular signal-related kinase (Erk)-signalling pathway to promote cell proliferation. b Activation of the TAM receptors recruits the interferon- $\alpha$ receptor
(IFNAR), leading to subsequent activation and nuclear translocation of signal transducer and activator of transcription 1 (Stat1). As a result, transcription of both suppressor of cytokine signalling (SOCS) 1 and 3 is increased, ultimately resulting in suppression of Toll-like receptor (TLR) and cytokine inflammatory cascades. c Mer can signal to induce phagocytosis via either an alpha(v) beta(5) integrin ( $\alpha \mathrm{v} \beta 5$-integrin)-dependent mechanism involving focal adhesion kinase (FAK) or via an alternative pathway involving Vav. Both pathways converge on Ras-related C3 botulinum toxin substrate (Rac), initiating cytoskeletal reorganisation and eventually leading to phagocytosis. tion of the Akt survival pathway, including nuclear translocation of nuclear factor $\kappa$-light-chain-enhancer of activated $B$ cells $(\mathrm{NF}-\kappa \mathrm{B})$ and upregulation of transcription of NF-кB-regulated genes [46, 58]. Alternatively, this pathway can be engaged indirectly by binding of the growth factor receptor-bound 2 (Grb2) adaptor protein, which can then bind PI3K [61]. It is of note that direct binding of PI3K sterically inhibits binding of Grb2. This is of particular importance in that it has been shown that Grb2 can engage the extracellular signal-related kinase (Erk) signalling pathway, which is the pathway by which TAMs signal proliferation (fig. 2a) [40, 60, 63, 64]. It has been shown that in human oligodendrocytes phosphorylation of Axl results in the recruitment of p85 and Grb2 to the receptor [61], although Gas6 does not appear to be a mitogen for oligodendrocytes. 


\section{Immunomodulation}

Although the earliest studies on the role of TAM receptor signalling concentrated on the role of this family in cell survival and proliferation, the generation of knockout mice lacking the individual receptors, along with doubleand triple-receptor knockouts, led to the discovery of the central role for the TAM receptors in immune regulation. Although even triple-knockout mice are viable and fertile, and develop apparently normally for the first few postnatal weeks, they develop a number of apparently degenerative phenotypes, the most dramatic of which is broadspectrum autoimmunity [65]. In triple-mutant animals there is hyper-proliferation of $\mathrm{B}$ and $\mathrm{T}$ cells from about 4 weeks of age, and the proliferation is such that ectopic colonies of these cells can be detected in almost every tissue [65]. The $\mathrm{B}$ and $\mathrm{T}$ cells of the triple-mutant mice are also constitutively active, leading to the triple-mutant mice developing symptoms similar to a wide range of autoimmune diseases, including rheumatoid arthritis and systemic lupus erythematosus [65]. Interestingly, the authors found that the dysregulation of $\mathrm{B}$ and $\mathrm{T}$ cells was not a cell-intrinsic phenomenon, but due primarily to the loss of TAM receptors in antigen-presenting cells such as macrophages and dendritic cells. These cell types are also constitutively active in TAM triple-knockout mice, and a loss of these receptors has been shown to lead to dysregulation of the innate immune system [66].

Unlike the signalling mechanisms involving PI3K to induce cell survival, the transduction of the anti-inflammatory effects of TAM receptors appears to involve the Janus kinase-signal transducer and activator of transcription (JAK-STAT) pathway [66]. It has recently become clear that the inhibition of inflammatory cytokine expression observed in a number of cell types is transduced through the recruitment of the type 1 interferon receptor (IFNAR), a receptor known to otherwise stimulate inflammation (fig. 2b) [66]. Further, it has been shown that the suppression of inflammation after induction of IFNAR stimulation is dependent upon TAM signalling, at least in dendritic cells [66]. Interestingly, a recent study by Prinz et al. [67] assessing mice devoid of IFNAR found an exacerbation of clinical symptoms in the experimental allergic encephalomyelitis model of demyelination, and this exacerbation was determined to be due to a loss of IFNAR signalling on cells of the innate immune system. Given the number and variety of cell types in which TAMs exert an immunomodulatory effect, TAM-dependent IFNAR signalling is not likely to be the only signalling pathway via which TAMs control immune activity, but at present other pathways remain to be elucidated.
Whilst much of the work examining the regulation of immune responses has focussed on antigen-presenting cells of the periphery, recent work has shown that TAM receptor signalling can also regulate the activation of microglia within the CNS. Work from our own laboratory has shown that pre-treatment of primary rat microglia in vitro with exogenous Gas6 can reduce the subsequent expression of the inflammatory cytokine TNF $\alpha$ by these microglia when activated by lipopolysaccharide challenge [31]. This work has been supported by work from Grommes et al. [68] who demonstrated that treatment of a mouse microglial cell line with Gas6 reduced expression of both inducible nitric oxide synthase and interleukin-1 $\beta$ after lipopolysaccharide challenge. Interestingly, the reduction in the inflammatory phenotype of the microglia observed by Grommes et al. [68] was accompanied by an increase in the phagocytic response (see below).

\section{Phagocytosis}

The structure of both Gas6 and protein S suggested that, in common with other Gla-domain containing proteins, both ligands would be able to bind negatively charged phospholipids such as PS. As discussed above, it was shown that Gas6 can specifically bind PS [23]. However, the biological relevance of this interaction was unclear until mice lacking all three TAM receptors were generated and assessed, with these mice being observed to have deficits in spermatogenesis and to develop blindness $[65,69]$. These apparently unrelated phenomena are in fact manifestations of the same underlying pathology - the failure of clearance of apoptotic cells as part of normal tissue homeostasis. The loss of germ cells in the testis is a result of the dysfunction of Sertoli cells, which fail to perform their normal function of clearance of the many apoptotic cells produced during normal spermatogenesis [69]. The blindness observed in TAM triple knockouts is also related to the failure of retinal pigment epithelial cells to phagocytose the distal ends of photoreceptors $[19,65,69]$. This phagocytosis is critical to the normal functioning of the retina. Indeed, it was found that Mer single knockout mice also showed this degenerative phenotype $[19,65]$, and that mutations in the Mer gene were responsible for retinal degeneration both in the rat and in humans [70-73].

The involvement of TAM receptor signalling, particularly that of Mer, has also been observed in other cell types. Of particular interest have been studies involving cells of the innate immune system such as macrophages and dendritic cells. Whilst many of these reports have 
focussed on Mer, it should be noted that a recent study has identified the involvement of all three TAM receptors in the clearance of apoptotic cells by peripheral macrophages and dendritic cells, with different cell types requiring different combinations of TAM receptors [74]. Further, a recent study has also shown that mice deficient in Gas6 have dysfunctional peripheral macrophages which have a reduced ability to clear apoptotic red blood cells [75].

Unlike signalling via TAM receptors for cell survival and inflammatory regulation, comparatively little is known about the intracellular signalling pathways involved in TAM-initiated phagocytosis. It is hypothesised that the binding of Gas6/protein S to PS on the surface of an apoptotic cell can form a bridge between the bound ligand and the receptor on a phagocyte (fig. 2c) [23, 76]. Some studies have demonstrated a connection between Mer signalling and $\alpha v \beta 5$-integrin, in which the Mer receptor and the $\alpha v \beta 5$-integrin receptor co-operate to amplify internalisation signals: this amplification occurs via Mer-dependent phosphorylation of focal adhesion kinase (FAK), binding of activated FAK to the $\alpha v \beta 5$-integrin receptor, and subsequent recruitment of a protein complex for Rac1 (Ras-related C3 botulinum toxin substrate 1) activation (fig. 2c) [77]. Whilst in some cells the presence of the $\alpha \mathrm{v} \beta 5$-integrin receptor appears to be required for Mer-dependent phagocytosis [77], it has nevertheless also been identified that in other cells the presence of the $\alpha v \beta 5$-integrin receptor does not appear to be necessary for Mer-dependent phagocytosis to occur [78]. In the study by Grommes et al. [68] described above, the Gas6induced phagocytosis by microglia was mediated by Vav phosphorylation, although this signalling mechanism also appeared to converge on the Rac pathway, initiating cytoskeletal reorganisation and eventually leading to phagocytosis (fig. 2c).

\section{TAM Signalling Can Regulate Myelination, Microglial Activation and Phagocytosis}

The above generic effects have specific relevance to the study of the molecular determinants of demyelination and remyelination within the CNS. This has been illustrated by recent work from our laboratory, which has recently studied the effect of the absence of Gas6 on cuprizone-mediated demyelination. Cuprizone is a copper chelator that, when fed to mice, initiates a reproducible and stereotyped focal demyelination, particularly of the corpus callosum $[79,80]$. This demyelination takes places in the absence of infiltration of the adaptive immune system and has been shown to be T-cell-independent [81]. In the cuprizone model of demyelination, there is a large recruitment of microglia/macrophages both before and during demyelination $[79,82]$. There is activation and proliferation of microglia and some infiltration of peripheral macrophages [82]. In addition to the effects on the innate immune system, there is loss of and damage to oligodendrocytes [83, 84]. As discussed above, studies of the newly forming MS lesions have shown that activation of microglia and oligodendrocyte apoptosis are some of the earliest events in the development of an MS lesion. Thus cuprizone-induced demyelination provides an excellent model system for studying these early events.

When Gas6 knockout mice are subjected to cuprizoneinduced demyelination for 3 weeks, both myelination and microglial activation are affected. In the absence of Gas6, oligodendrocyte survival is compromised, with the result that, in comparison to wild-type mice, fewer oligodendrocytes can be detected both in the rostral and caudal corpus callosum. This loss of oligodendrocytes is accompanied by a reduction in overall myelination and fewer myelinated axons. In contrast, a study by Hoehn et al. [85], in which Axl knockout mice were challenged with cuprizone, did not observe any significant loss of oligodendrocytes in comparison with wild-type mice at any time point examined. However, the authors of this study did observe a reduction in overall myelination after 6 weeks of cuprizone challenge in Axl knockout mice. This apparent conflict between the relative effect on oligodendrocyte survival in the absence of Gas6 compared to the absence of the Axl receptor suggests that a loss of signalling through a single receptor $(\mathrm{Axl})$ has a less profound effect than a reduction in signalling through all three receptors, such as in the absence of the ligand Gas6. Alternatively, it may be that either Tyro3 or Mer is the main TAM receptor responsible for transducing the anti-apoptotic effect of Gas6 in the context of cuprizone challenge.

In addition to a loss of oligodendrocytes and reduction in myelination, when Gas6 knockout mice are subjected to cuprizone challenge, there is a profound increase in $\mathrm{mi}-$ croglial activation. The number of microglia detected in the corpus callosum of Gas 6 knockout mice is significantly greater than in wild-type mice after 3 weeks of cuprizone challenge [31]. However, this study was limited to an examination of the effects of 3 weeks of cuprizone challenge. This study therefore provides only a single 'snapshot' of oligodendrocyte survival and microglial activation, and it is not possible to formally resolve which effects are the direct result of a loss of Gas 6 and which, if any, are 
secondary. In the study described above by Hoehn et al. [85] of Axl knockout mice, the authors examined a number of time points both during and after cuprizone-mediated demyelination. Again, in contrast to the findings in Gas6 knockout mice, the authors did not observe an increase in the number of microglia, but rather a significant decrease in microglia in Axl knockout mice after 4 weeks of cuprizone challenge. The authors also found that in the absence of Axl, there appeared to be a delay in phagocytosis and therefore the removal of myelin debris. Again, this apparent disparity in results between the 2 studies could reflect the ability of alternate members of the TAM receptor family to compensate for the loss of a single receptor, whereas the overall reduction in signalling that accompanies the loss of the ligand for these receptors could outstrip the ability of, for example, protein $S$ to compensate for this loss. Additionally, it will be important to determine the phagocytic ability of microglia in the absence of Gas6 signalling. Whilst many more microglia are observed in the corpus callosum in the absence of Gas6, the phenotype of these microglia remains undetermined. It could be that, in the context of Gas 6 deficiency, these cells have a pro-inflammatory phenotype, secreting cytotoxic cytokines and reactive oxygen species, rather than a more anti-inflammatory and phagocytic and immunomodulatory phenotype, which in other contexts would be responsible for the removal of myelin debris and apoptotic cell bodies, as well as contributing to repair.

\section{Conclusions}

The TAM receptors are unique amongst the larger family of receptor tyrosine kinases in that their expression is upregulated during postnatal development. Consistent with the expression data are the observations that knockout of either the ligand Gas6, or of all three receptors, still leads to viable mice, indicating that signalling via TAM receptors is not essential for embryonic development. However, studies of these knockout animals have also shown that TAM receptor signalling is central to many ongoing processes in the postnatal and adult animal.

Of particular interest is the important role that TAM receptor signalling plays in controlling three major processes: cell survival and proliferation, immunomodulation and phagocytosis. Of relevance to this review, it is apparent that these three processes are of central importance in the initiation and development of MS. We and others have shown that Gas6 is an important modulator of both oligodendrocyte survival and microglial pheno- type both in vitro and in vivo. Further, the expression pattern of the TAM receptors hint at a potential role for TAM receptor signalling in the direct control of myelination, not just as a secondary outcome of its anti-apoptotic effects on oligodendrocytes.

As discussed previously, until very recently confusion has reigned concerning the status of protein $S$ as a genuine ligand for the TAM receptors. In consequence, examination of the effects of protein $S$ in various biological systems lags well behind that of Gas6, with the notable exception of its effects on retinal pigment epithelial cells. There are tantalising hints of the potential role that protein $\mathrm{S}$ could play in limiting injury in CNS disorders such as MS. For example, the findings that exogenous protein $\mathrm{S}$ can limit astrocyte proliferation and, by extension, potentially limit glial scar development, the formation of which can impede remyelination. It is therefore of critical importance that the biological effects of protein $S$ on TAM receptor signalling are more closely investigated.

In demyelinating diseases as MS, which have a clear immune component, there is an important interplay between cell survival, phagocytosis and immune regulation. Efficient phagocytosis of apoptotic cells and myelin debris is an essential first step in remyelination, as myelin debris has been shown to inhibit remyelination [86, 87]. Further, it is very likely that the broad-spectrum autoimmunity observed in TAM receptor triple-mutant mice results not only from the failure of immune regulation, but at least in part from the potentiated availability and presentation of autoantigens as a consequence of the failure of removal of apoptotic cells [8]. Thus, it could be hypothesised that dysfunctional or reduced TAM receptor signalling could create a 'vicious cycle' of cell death, failure of phagocytosis, inhibition of remyelination, and immune hyperactivation.

Much of the work discussed above has been performed in rodents or in vitro models of disease. Human work has been limited, but promising. Gas6 has been shown to be a pro-survival factor for human oligodendrocytes, and Gas6 protein has been shown to be upregulated in the CSF of patients with a chronic inflammatory demyelinating disease. Extending these studies to the CSF of patients with MS would be of interest and potentially revealing, but is hampered by the fact that collection of CSF is currently not a routine procedure in the management of MS. Nevertheless, it is clear that an important first step in determining whether TAM signalling also plays a biologically significant role in MS pathology will be to establish the expression profiles of TAM receptors and the ligands in human MS lesions. 


\section{References}

1 Barnett MH, Prineas JW: Relapsing and remitting multiple sclerosis: pathology of the newly forming lesion. Ann Neurol 2004;55: 458-468.

-2 Butzkueven H, Zhang JG, Soilu-Hanninen M, Hochrein H, Chionh F, Shipham KA, Emery B, Turnley AM, Petratos S, Ernst M, Bartlett PF, Kilpatrick TJ: LIF receptor signaling limits immune-mediated demyelination by enhancing oligodendrocyte survival. Nat Med 2002;8:613-619.

$\checkmark 3$ Marriott MP, Emery B, Cate HS, Binder MD, Kemper D, Wu Q, Kolbe S, Gordon IR, Wang H, Egan G, Murray S, Butzkueven H, Kilpatrick TJ: Leukemia inhibitory factor signaling modulates both central nervous system demyelination and myelin repair. Glia 2008;56: 686-698.

4 Lai C, Lemke G: An extended family of protein-tyrosine kinase genes differentially expressed in the vertebrate nervous system. Neuron 1991;6:691-704.

5 Janssen JW, Schulz AS, Steenvoorden AC, Schmidberger M, Strehl S, Ambros PF, Bartram CR: A novel putative tyrosine kinase receptor with oncogenic potential. Oncogene 1991;6:2113-2120.

6 O’Bryan JP, Frye RA, Cogswell PC, Neubauer A, Kitch B, Prokop C, Espinosa R 3rd, Le Beau MM, Earp HS, Liu ET: Axl, a transforming gene isolated from primary human myeloid leukemia cells, encodes a novel receptor tyrosine kinase. Mol Cell Biol 1991;11: 5016-5031.

7 Rescigno J, Mansukhani A, Basilico C: A putative receptor tyrosine kinase with unique structural topology. Oncogene 1991;6:19091913.

$>8$ Lemke G, Rothlin CV: Immunobiology of the TAM receptors. Nat Rev Immunol 2008; 8:327-336.

-9 Sasaki T, Knyazev PG, Clout NJ, Cheburkin Y, Gohring W, Ullrich A, Timpl R, Hohenester E: Structural basis for Gas6-Axl signalling. EMBO J 2006;25:80-87.

-10 Schneider C, King RM, Philipson L: Genes specifically expressed at growth arrest of mammalian cells. Cell 1988;54:787-793.

-11 Manfioletti G, Brancolini C, Avanzi G, Schneider C: The protein encoded by a growth arrest-specific gene (gas6) is a new member of the vitamin K-dependent proteins related to protein $\mathrm{S}$, a negative coregulator in the blood coagulation cascade. Mol Cell Biol 1993;13:4976-4985.

12 Walker FJ: Regulation of activated protein C by a new protein. A possible function for bovine protein S. J Biol Chem 1980;255:55215524.

13 DiScipio RG, Davie EW: Characterization of protein S, a gamma-carboxyglutamic acid containing protein from bovine and human plasma. Biochemistry 1979;18:899-904.
14 Nagata K, Ohashi K, Nakano T, Arita H, Zong C, Hanafusa H, Mizuno K: Identification of the product of growth arrest-specific gene 6 as a common ligand for Axl, Sky, and Mer receptor tyrosine kinases. J Biol Chem 1996;271:30022-30027.

15 Ohashi K, Nagata K, Toshima J, Nakano T, Arita $\mathrm{H}$, Tsuda $\mathrm{H}$, Suzuki K, Mizuno K: Stimulation of sky receptor tyrosine kinase by the product of growth arrest-specific gene 6. J Biol Chem 1995;270:22681-22684.

16 Stitt TN, Conn G, Gore M, Lai C, Bruno J, Radziejewski C, Mattsson K, Fisher J, Gies DR, Jones PF, et al: The anticoagulation factor protein $\mathrm{S}$ and its relative, Gas6, are ligands for the Tyro 3/Axl family of receptor tyrosine kinases. Cell 1995;80:661-670.

$\checkmark 17$ Godowski PJ, Mark MR, Chen J, Sadick MD, Raab H, Hammonds RG: Reevaluation of the roles of protein $\mathrm{S}$ and Gas6 as ligands for the receptor tyrosine kinase Rse/Tyro 3. Cell 1995;82:355-358.

18 Hall MO, Obin MS, Heeb MJ, Burgess BL, Abrams TA: Both protein S and Gas6 stimulate outer segment phagocytosis by cultured rat retinal pigment epithelial cells. Exp Eye Res 2005;81:581-591.

-19 Prasad D, Rothlin CV, Burrola P, BurstynCohen T, Lu Q, Garcia de Frutos P, Lemke G: TAM receptor function in the retinal pigment epithelium. Mol Cell Neurosci 2006;33. 96-108.

20 Dahlback B, Lundwall A, Stenflo J: Primary structure of bovine vitamin K-dependent protein S. Proc Natl Acad Sci USA 1986;83: 4199-4203.

-21 Lundwall A, Dackowski W, Cohen E, Shaffer M, Mahr A, Dahlback B, Stenflo J, Wydro R: Isolation and sequence of the cDNA for human protein $\mathrm{S}$, a regulator of blood coagulation. Proc Natl Acad Sci USA 1986;83:67166720.

22 Bellido-Martin L, de Frutos PG: Vitamin Kdependent actions of Gas6. Vitam Horm 2008;78:185-209.

23 Nakano T, Ishimoto Y, Kishino J, Umeda M, Inoue K, Nagata K, Ohashi K, Mizuno K, Arita $\mathrm{H}$ : Cell adhesion to phosphatidylserine mediated by a product of growth arrestspecific gene 6. J Biol Chem 1997;272:2941129414.

24 Uehara H, Shacter E: Auto-oxidation and oligomerization of protein $\mathrm{S}$ on the apoptotic cell surface is required for Mer tyrosine kinase-mediated phagocytosis of apoptotic cells. J Immunol 2008;180:2522-2530.

25 Mark MR, Chen J, Hammonds RG, Sadick M, Godowsk PJ: Characterization of Gas6, a member of the superfamily of $\mathrm{G}$ domaincontaining proteins, as a ligand for Rse and Axl. J Biol Chem 1996;271:9785-9789.
26 Tanabe K, Nagata K, Ohashi K, Nakano T, Arita H, Mizuno K: Roles of gamma-carboxylation and a sex hormone-binding globulin-like domain in receptor-binding and in biological activities of Gas6. FEBS Lett 1997; 408:306-310.

27 Pierce A, Bliesner B, Xu M, Nielsen-Preiss S, Lemke G, Tobet S, Wierman ME: Axl and Tyro3 modulate female reproduction by influencing gonadotropin-releasing hormone neuron survival and migration. Mol Endocrinol 2008;22:2481-2495.

28 Lai C, Gore M, Lemke G: Structure, expression, and activity of Tyro 3 , a neural adhesion-related receptor tyrosine kinase. Oncogene 1994;9:2567-2578.

$\checkmark 29$ Prieto AL, Weber JL, Lai C: Expression of the receptor protein-tyrosine kinases Tyro-3, Axl, and Mer in the developing rat central nervous system. J Comp Neurol 2000;425: 295-314.

30 Mark MR, Scadden DT, Wang Z, Gu Q, Goddard A, Godowski PJ: Rse, a novel receptortype tyrosine kinase with homology to Axl/ Ufo, is expressed at high levels in the brain. J Biol Chem 1994;269:10720-10728.

-31 Binder MD, Cate HS, Prieto AL, Kemper D, Butzkueven H, Gresle MM, Cipriani T, Jokubaitis VG, Carmeliet P, Kilpatrick TJ: Gas6 deficiency increases oligodendrocyte loss and microglial activation in response to cuprizone-induced demyelination. J Neurosci 2008;28:5195-5206

32 Kilpatrick TJ, Ortuno D, Bucci T, Lai C, Lemke G: Rat oligodendroglia express c-met and focal adhesion kinase, protein tyrosine kinases implicated in regulating epithelial cell motility. Neurosci Lett 2000;279:5-8.

33 Prieto AL, O’Dell S, Varnum B, Lai C: Localization and signaling of the receptor protein tyrosine kinase Tyro3 in cortical and hippocampal neurons. Neuroscience 2007;150: 319-334.

-34 Prieto AL, Weber JL, Tracy S, Heeb MJ, Lai C: Gas6, a ligand for the receptor protein-tyrosine kinase Tyro-3, is widely expressed in the central nervous system. Brain Res 1999; 816:646-661.

35 Li R, Chen J, Hammonds G, Phillips H, Armanini M, Wood P, Bunge R, Godowski PJ, Sliwkowski MX, Mather JP: Identification of Gas6 as a growth factor for human Schwann cells. J Neurosci 1996;16:2012-2019.

$>36$ He X, Shen L, Bjartell A, Dahlback B: The gene encoding vitamin K-dependent anticoagulant protein $\mathrm{S}$ is expressed in multiple rabbit organs as demonstrated by northern blotting, in situ hybridization, and immunohistochemistry. J Histochem Cytochem 1995;43:85-96.

>37 Yanagita M, Ishii K, Ozaki H, Arai H, Nakano T, Ohashi K, Mizuno K, Kita T, Doi T: Mechanism of inhibitory effect of warfarin on mesangial cell proliferation. J Am Soc Nephrol 1999; 10:2503-2509. 
>38 Yin JL, Pilmore HL, Yan YQ, McCaughan GW, Bishop GA, Hambly BD, Eris JM: Expression of growth arrest-specific gene 6 and its receptors in a rat model of chronic renal transplant rejection. Transplantation 2002; 73:657-660.

39 Bellosta P, Zhang Q, Goff SP, Basilico C: Signaling through the ARK tyrosine kinase receptor protects from apoptosis in the absence of growth stimulation. Oncogene 1997; 15:2387-2397.

40 Goruppi S, Ruaro E, Schneider C: Gas6, the ligand of Axl tyrosine kinase receptor, has mitogenic and survival activities for serum starved NIH3T3 fibroblasts. Oncogene 1996; 12:471-480.

41 Valverde P, Obin MS, Taylor A: Role of Gas6/ Axl signaling in lens epithelial cell proliferation and survival. Exp Eye Res 2004;78:2737.

42 Nakano T, Kawamoto K, Higashino K, Arita $\mathrm{H}$ : Prevention of growth arrest-induced cell death of vascular smooth muscle cells by a product of growth arrest-specific gene, Gas 6 . FEBS Lett 1996;387:78-80.

43 Son BK, Kozaki K, Iijima K, Eto M, Kojima T, Ota H, Senda Y, Maemura K, Nakano T, Akishita M, Ouchi Y: Statins protect human aortic smooth muscle cells from inorganic phosphate-induced calcification by restoring Gas6-Axl survival pathway. Circ Res 2006;98:1024-1031.

-44 D’Arcangelo D, Gaetano C, Capogrossi MC: Acidification prevents endothelial cell apoptosis by Axl activation. Circ Res 2002;91:e4e12.

45 O’Donnell K, Harkes IC, Dougherty L, Wicks IP: Expression of receptor tyrosine kinase Axl and its ligand Gas6 in rheumatoid arthritis: evidence for a novel endothelial cell survival pathway. Am J Pathol 1999;154: 1171-1180.

-46 Hasanbasic I, Cuerquis J, Varnum B, Blostein MD: Intracellular signaling pathways involved in Gas6-Axl-mediated survival of endothelial cells. Am J Physiol Heart Circ Physiol 2004;287:H1207-H1213.

-47 Chan MC, Mather JP, McCray G, Lee WM: Identification and regulation of receptor tyrosine kinases Rse and Mer and their ligand Gas6 in testicular somatic cells. J Androl 2000;21:291-302.

-48 Anwar A, Keating AK, Joung D, Sather S, Kim GK, Sawczyn KK, Brandao L, Henson PM, Graham DK: Mer tyrosine kinase (MerTK) promotes macrophage survival following exposure to oxidative stress. J Leukoc Biol 2009;86:73-79.

-49 Allen MP, Zeng C, Schneider K, Xiong X, Meintzer MK, Bellosta P, Basilico C, Varnum B, Heidenreich KA, Wierman ME: Growth arrest-specific gene 6 (Gas6)/adhesion related kinase (Ark) signaling promotes gonadotropin-releasing hormone neuronal survival via extracellular signal-regulated kinase (ERK) and Akt. Mol Endocrinol 1999;13: 191-201.
50 Yagami T, Ueda K, Asakura K, Sakaeda T, Nakazato H, Kuroda T, Hata S, Sakaguchi G, Itoh N, Nakano T, Kambayashi Y, Tsuzuki H Gas6 rescues cortical neurons from amyloid beta protein-induced apoptosis. Neuropharmacology 2002;43:1289-1296.

51 Shankar SL, O’Guin K, Cammer M, McMorris FA, Stitt TN, Basch RS, Varnum B, ShafitZagardo B: The growth arrest-specific gene product Gas6 promotes the survival of human oligodendrocytes via a phosphatidylinositol 3-kinase-dependent pathway. J Neurosci 2003;23:4208-4218.

52 Shankar SL, O’Guin K, Kim M, Varnum B Lemke G, Brosnan CF, Shafit-Zagardo B: Gas6/Axl signaling activates the phosphatidylinositol 3-kinase/Akt1 survival pathway to protect oligodendrocytes from tumor necrosis factor alpha-induced apoptosis. J Neurosci 2006;26:5638-5648.

53 Liu D, Guo H, Griffin JH, Fernandez JA, Zlokovic BV: Protein S confers neuronal protection during ischemic/hypoxic injury in mice. Circulation 2003;107:1791-1796.

54 Stenhoff J, Dahlback B, Hafizi S: Vitamin Kdependent Gas6 activates ERK kinase and stimulates growth of cardiac fibroblasts. Biochem Biophys Res Commun 2004;319: 871-878.

55 Benzakour O, Formstone C, Rahman S, Kanthou C, Dennehy U, Scully MF, Kakkar VV, Cooper DN: Evidence for a protein S receptor(s) on human vascular smooth muscle cells. Analysis of the binding characteristics and mitogenic properties of protein S on human vascular smooth muscle cells. Biochem J 1995;308:481-485.

56 Tomobe YI, Hama H, Sakurai T, Fujimori A, Abe Y, Goto K: Anticoagulant factor protein $\mathrm{S}$ inhibits the proliferation of rat astrocytes after injury. Neurosci Lett 1996;214:57-60.

57 Konishi A, Aizawa T, Mohan A, Korshunov VA, Berk BC: Hydrogen peroxide activates the Gas6-Axl pathway in vascular smooth muscle cells. J Biol Chem 2004;279:2876628770.

-58 Demarchi F, Verardo R, Varnum B, Brancolini C, Schneider C: Gas6 anti-apoptotic signaling requires $\mathrm{NF}$-kappa $\mathrm{B}$ activation. J Biol Chem 2001;276:31738-31744.

59 Goruppi S, Chiaruttini C, Ruaro ME, Varnum B, Schneider C: Gas6 induces growth, beta-catenin stabilization, and T-cell factor transcriptional activation in contact-inhibited C57 mammary cells. Mol Cell Biol 2001; 21:902-915.

60 Goruppi S, Ruaro E, Varnum B, Schneider C: Requirement of phosphatidylinositol 3-kinase-dependent pathway and Src for Gas6Axl mitogenic and survival activities in NIH 3T3 fibroblasts. Mol Cell Biol 1997; 17:44424453.
61 Weinger JG, Gohari P, Yan Y, Backer JM, Varnum B, Shafit-Zagardo B: In brain, Axl recruits Grb2 and the $\mathrm{p} 85$ regulatory subunit of PI3 kinase; in vitro mutagenesis defines the requisite binding sites for downstream Akt activation. J Neurochem 2008;106:134146.

62 Braunger J, Schleithoff L, Schulz AS, Kessler H, Lammers R, Ullrich A, Bartram CR, Janssen JW: Intracellular signaling of the Ufo/ Axl receptor tyrosine kinase is mediated mainly by a multi-substrate docking-site. Oncogene 1997;14:2619-2631.

63 Fridell YW, Jin Y, Quilliam LA, Burchert A, McCloskey P, Spizz G, Varnum B, Der C, Liu ET: Differential activation of the Ras/extracellular-signal-regulated protein kinase pathway is responsible for the biological consequences induced by the Axl receptor tyrosine kinase. Mol Cell Biol 1996;16:135-145.

64 Goruppi S, Ruaro E, Varnum B, Schneider C: Gas6-mediated survival in NIH3T3 cells activates stress signalling cascade and is independent of Ras. Oncogene 1999;18:42244236.

$65 \mathrm{Lu}$ Q, Lemke G: Homeostatic regulation of the immune system by receptor tyrosine $\mathrm{ki}$ nases of the Tyro 3 family. Science 2001;293: 306-311.

66 Rothlin CV, Ghosh S, Zuniga EI, Oldstone $\mathrm{MB}$, Lemke G: TAM receptors are pleiotropic inhibitors of the innate immune response. Cell 2007;131:1124-1136.

67 Prinz M, Schmidt H, Mildner A, Knobeloch KP, Hanisch UK, Raasch J, Merkler D, Detje C, Gutcher I, Mages J, Lang R, Martin R, Gold R, Becher B, Brück W, Kalinke U: Distinct and nonredundant in vivo functions of IFNAR on myeloid cells limit autoimmunity in the central nervous system. Immunity 2008;28:675-686.

68 Grommes C, Lee CY, Wilkinson BL, Jiang Q, Koenigsknecht-Talboo JL, Varnum B, Landreth GE: Regulation of microglial phagocytosis and inflammatory gene expression by Gas6 acting on the Axl/Mer family of tyrosine kinases. J Neuroimmune Pharmacol 2008;3:130-140.

-69 Lu Q, Gore M, Zhang Q, Camenisch T, Boast S, Casagranda F, Lai C, Skinner MK, Klein R, Matsushima GK, Earp HS, Goff SP, Lemke G: Tyro-3 family receptors are essential regulators of mammalian spermatogenesis. $\mathrm{Na}$ ture 1999;398:723-728.

70 D'Cruz PM, Yasumura D, Weir J, Matthes MT, Abderrahim H, LaVail MM, Vollrath D: Mutation of the receptor tyrosine kinase gene Mertk in the retinal dystrophic RCS rat. Hum Mol Genet 2000;9:645-651.

71 Gal A, Li Y, Thompson DA, Weir J, Orth U, Jacobson SG, Apfelstedt-Sylla E, Vollrath D: Mutations in MERTK, the human orthologue of the RCS rat retinal dystrophy gene, cause retinitis pigmentosa. Nat Genet 2000; 26:270-271. 
-72 McHenry CL, Liu Y, Feng W, Nair AR, Feathers KL, Ding X, Gal A, Vollrath D, Sieving PA, Thompson DA: MERTK arginine-844cysteine in a patient with severe rod-cone dystrophy: loss of mutant protein function in transfected cells. Invest Ophthalmol Vis Sci 2004;45:1456-1463.

-73 Tschernutter M, Jenkins SA, Waseem NH, Saihan Z, Holder GE, Bird AC, Bhattacharya SS, Ali RR, Webster AR: Clinical characterisation of a family with retinal dystrophy caused by mutation in the Mertk gene. Br J Ophthalmol 2006;90:718-723.

-74 Seitz HM, Camenisch TD, Lemke G, Earp HS, Matsushima GK: Macrophages and dendritic cells use different Axl/Mertk/Tyro3 receptors in clearance of apoptotic cells. J Immunol 2007; 178:5635-5642.

-75 Angelillo-Scherrer A, Burnier L, Lambrechts D, Fish RJ, Tjwa M, Plaisance S, Sugamele R, DeMol M, Martinez-Soria E, Maxwell PH, Lemke G, Goff SP, Matsushima GK, Earp HS, Chanson M, Collen D, Izui S, Schapira M, Conway EM, Carmeliet P: Role of Gas6 in erythropoiesis and anemia in mice. J Clin Invest 2008;118:583-596.

-76 Anderson HA, Maylock CA, Williams JA, Paweletz CP, Shu H, Shacter E: Serum-derived protein $\mathrm{S}$ binds to phosphatidylserine and stimulates the phagocytosis of apoptotic cells. Nat Immunol 2003;4:87-91.
77 Wu Y, Singh S, Georgescu MM, Birge RB: A role for Mer tyrosine kinase in alphavbeta5 integrin-mediated phagocy tosis of apoptotic cells. J Cell Sci 2005;118:539-553.

78 Hall MO, Abrams TA, Burgess BL: Integrin alphavbeta 5 is not required for the phagocytosis of photoreceptor outer segments by cultured retinal pigment epithelial cells. Exp Eye Res 2003;77:281-286.

79 Hiremath MM, Saito Y, Knapp GW, Ting JP, Suzuki K, Matsushima GK: Microglial/macrophage accumulation during cuprizoneinduced demyelination in C57BL/6 mice. J Neuroimmunol 1998;92:38-49.

80 Matsushima GK, Morell P: The neurotoxicant, cuprizone, as a model to study demyelination and remyelination in the central nervous system. Brain Pathol 2001;11:107116.

81 Hiremath MM, Chen VS, Suzuki K, Ting JP, Matsushima GK: MHC class II exacerbates demyelination in vivo independently of $\mathrm{T}$ cells. J Neuroimmunol 2008;203:23-32.

82 McMahon EJ, Suzuki K, Matsushima GK: Peripheral macrophage recruitment in cuprizone-induced CNS demyelination despite an intact blood-brain barrier. J Neuroimmunol 2002;130:32-45.
83 Mason JL, Jones JJ, Taniike M, Morell P, Suzuki K, Matsushima GK: Mature oligodendrocyte apoptosis precedes IGF-1 production and oligodendrocyte progenitor accumulation and differentiation during demyelination/remyelination. J Neurosci Res 2000;61:251-262.

84 Morell P, Barrett CV, Mason JL, Toews AD, Hostettler JD, Knapp GW, Matsushima GK: Gene expression in brain during cuprizoneinduced demyelination and remyelination. Mol Cell Neurosci 1998;12:220-227.

$>85$ Hoehn HJ, Kress Y, Sohn A, Brosnan CF, Bourdon S, Shafit-Zagardo B: Axl-/- mice have delayed recovery and prolonged axonal damage following cuprizone toxicity. Brain Res 2008;1240:1-11.

86 Kotter MR, Zhao C, van Rooijen N, Franklin RJ: Macrophage-depletion induced impairment of experimental CNS remyelination is associated with a reduced oligodendrocyte progenitor cell response and altered growth factor expression. Neurobiol Dis 2005; 18 : 166-175.

87 Miller RH: Contact with central nervous system myelin inhibits oligodendrocyte progenitor maturation. Dev Biol 1999;216:359368 